Francois Tran, Özlem Lamonte-Berk

The changes in Architecture Etrminology

\title{
Francois Tran
}

Professor

Ecole nationale Superieure d'Architecture de Lyon

France

francois.tran@lyon.archi.fr

\section{Özlem Lamonte-Berk}

Professor

Ecole nationale Superieure d'Architecture de Lyon

France

ozlem.lamontre-berk@lyon.archi.fr 
Francois Tran, Özlem Lamonte-Berk

\section{The Changes in Architecture Terminology}

The intention of this research is to inspire a discussion about the changes in architecture terminology with the revolution in communication and representation forms as a result of digitalisation. The blurred boundary between the virtual and the analogue worlds, the misunderstandings and the confusion that appear with the interaction of these two worlds nowadays form the major problems facing architectural design, education and research. The researchers in this field are focused on the interface, the meeting and the transformation point between the digital and analogue worlds in order to prevent those problems and confusions. One of the main reasons of this ambiguity is the architectural terminology that changes according to the changing status of architectural representation i.e. new forms of representation; new forms of communication i.e. the new role of the architect and the researcher.

Whenever and wherever information and knowledge specialised is created, communicated or transformed terminology is involved in a way or another. An absence of terminology is combined with an absence of an understanding of concepts. Therefore with the new information and communication technologies; new and developing subject areas the existence of terminology and its update is indispensable. Thus the changing status of the terminology must be analysed.

As architecture terminology is essential to improve today's challenging, multidisciplinary communication in order to clarify the problems of ambiguity and unawareness (as a result of shift of specific architectural vocabulary) it is necessary to analyse the changes in the architectural terminology which will form the discussion point of the following paper.

As this paper is the beginning step of a research project which started on the occasion of the conference proposed by EAAE/ARCC we will here present only the objectives of this research, its general problematics, the methods that we wish to develop and some provisional results like the illustration of this approach to be followed.

\section{Introduction}

The principal aim of this research is to observe the evolution of the vocabulary used in the field of architecture in the last 50 years. The challenge is initially on the epistemological level. Indeed in a cultural context that some named Post-modern (Lyotard, 1977) and which could be characterized by the end of the universal reasons and a dissemination of the individual enunciations, any theory as forms organized of concepts, offering a comprehension of architecture would become impossible. It is then the advent of multiple doctrines like as many discourses giving an interpretation of the architecture directed towards the action starting from presumedly true concepts. From this moment architecture takes place in a project of society in relation to a practice in conformity with an ethics.

67 - ARCC Journal / Volume 5 Issue 2 - 67 
The discourses on architecture become more and more unstable as a result of their own temporalities and changing referents. For example digital architecture calls into question the traditional forms of perception and suggests the advent of a new subjectivity.

We propose to seize these changes through the analysis of the discourses by identifying the new paradigms of architecture by making the assumption that it is in the interdiscourses or in the intertexts that a theory of architecture remains possible. Indeed the thought is not any more the characteristic of only one group of authors or a single theoretical space but takes part of a process of circulation of the ideas and practices which converge at a given time.

\section{Method}

The analysis of a discourse consists initially of a lexicological analysis using the tools of the lexicostatistics (or lexical statistics) which measures the frequency of the words in a text or a corpus of texts. This operation is automated by the use of certain suitable software of lexicographical analysis. It results in setting up a list of the most used words who characterize the lexicon of each author. In the second time, it is a question of carrying out a comparison of the lexicons to establish a typology of the authors and to determine their universes of reference that we call 'paradigms'.

In this first phase we put temporarily aside on one hand the question of the context i.e. all the extra linguistic determinations of the discourses which are related to the components of the situation of enunciation and on the other hand the question of lexical morphology and in particular the creation of neologisms which characterize a speech of speciality.

The study develops from both diachronic and synchronic point of view: The diachronic analysis seizes the semantic evolution of the words or their appearances as their disappearances or even their rarefaction in the discourses on architecture. Let us note that the same words used during different periods can correspond to different concepts according to ' universes of reference' to which they belong. Also the lexicological analysis makes it possible to see the appearing of a word in a corpus, and to see who has introduced it and on which date in order to create its history. The synchronic analysis aims to identify through the words employed in the discourses the universes of references which characterise the contemporary tendencies of architecture

\subsection{Constitution of the corpus}

The materials of study are the discourses on architecture and among all the forms of those discourses we will privilege the texts i.e. any discourse fixed by writing.

The corpus must be made up according to the principle of homogeneity: all the selected texts are on architecture even if their authors have different statutes (architects, urban planners, philosophers, theorists, historians, educators, researchers, critics, designers, artists, journalists...) The principle of the 'reputation' of the authors has been taken into consideration in order to be able to be sure of the presence of the actors of the architectural debate over this period (being known either by their works in the professional or academic field, or by the prestigious prizes or awards obtained, or by their media influence...).

Several texts of the same author belonging to the same period or to different periods can be

68 - ARCC Journal / Volume 5 Issue 2 - 68 
presents in the corpus. They will make it possible to observe the evolution or the stability of the architecture terminology used by this author at the same time in 'time' and in 'space' of the theoretical or doctrinal positions.

The nature of the texts varies from an interview to a book, an article or a conference with various supports as architectural periodicals, scientific reviews, academic works, books, Internet sites, search engines specialized in architecture and sciences, newspapers.

In a later phase of the research, it will be necessary to distinguish the corpus according to the nature of their support, or the status of their authors in order to try to evaluate the impact of the forms of communication on the diffusion of the vocabulary of architecture and its theoretical effect.

The corpus currently includes 193 texts (both in English and in French) of 113 authors or author groups and consists the period from 1960 to 2008. Thereafter the corpus will be enlarged till 1955 to validate the diachronic study. The date '1955' has been proposed by Charles Jencks in his work "Language of Post-Modern Architecture" (1979) to establish a typology of the architects according to the tendencies that he had noticed till 1980. This approach will possibly enable us to verify the interpretation of our own typology.

For the synchronic study we chose to consider periods of 10 years (in future, as the research progresses these periods will be transformed to 5 years).

The period 1960 - 1969 consists of 26 texts and 19 authors as the period $1970-1979$ includes 28 texts and 20 authors. The period $1980-1989$ is formed of 34 texts and 28 authors. The period of 1990 - 1999 includes 40 texts and 31 authors. The last period $2000-2008$ is made up of 8 years and consists of 66 texts and 50 authors.

The length of the texts is variable between 215 and 11611 words for the current corpus. This corpus that we analyse here is composed of both English and French texts. The French texts will be the subject of translation.

\subsection{The analysis}

In the first phase of this research, we considered the texts of 5 periods (each of 10 years) from 1960 to 2008 and the results presented hereafter are related to those periods.

\subsection{Lexicon}

The method is at the same time inductive and then deductive: in fact the words identified by the lexicostatistics make it possible to set up a first list from which we retain the terms that are in connection with the field of architecture to establish the lexical and semantic field. For each text, the first 10 words the most used (frequency or a number of occurrences) among the substantives and the adjectives were retained to lead to the alphabetical index (see Annexes 'List 1').

This analysis also permits us to realize the necessary comparison between the 5 periods by identifying the repeating terms ( as architecture, aesthetics, building, culture, construction, history, nature, etc.), the new terms (as interactivity, interface, internet, hybrid, software, etc.), the new values (as ecology, green design, sustainable development, digital, virtual, etc.), the new meanings (as machine, surface, skin, etc.), or the words which rarefy (as function, theory, etc.)

69 - ARCC Journal / Volume 5 Issue 2 - 69 
posing the assumption of a language of generations. As the result of this analysis we can develop a hypothesis saying that there is a formal structure of the discourses on architecture but in time the content changes.

To hold account of the number of repetitions of the same word of a text and therefore of its real value we developed a system of 'balancing-ponderation' in order to establish a classification of the words most used for the whole of the corpus. The principle aim of this analysis is to clarify the difference of the placement of the word as the range therefore the value changes from the 1 st to the 10th place. For example in the period of 2000-2008 the word 'Architecture' has a value of '252' and the word 'Conception' is the last word of the ponderation list with a value of ' 1 '.

The 'Table of Ponderation' -listed below- shows the first 10 words (and their values) that take place in the lists of each of the 5 periods. That permits us to see the words that were the most important and frequent ones and their evolution in 50 years period.

The next phase of the research is to bring out the words that exist in each of the 5 periods and to repeat the lexicostatistic analysis - as we call 'Phase 2' - in order to set up a second list of terms that are in connection with the field of architecture. That enables us to deepen the analysis of each text and to identify the new terms, the universes of reference to which they belong to and the evolution of those universes of reference. The words that are frequently used in each period can be listed as - aesthetics, art, building, city, complex, culture, design, energy, environment, form, history, human, life, idea, ideology, image, language, meaning, nature, natural, modern(ism), pattern, people, place, post-modern(ism), project, structure, system, technique, technology, theory, work, world. As a result of the lexicostatistic analysis of 'Phase2' for the period of 2000-2008 we were able to bring out 118 new terms that enabled us to deepen in the content of the texts, therefore the new discussion subjects, values and possible theories on architecture. Some of these new terms can be listed as -architectextile, argue, censure, crisis, elasticity, internet, manifestation, mathematics, metaphor, politics, prototype, screen, sequence, sustainable, tectonic, virtual-reality, vision, etc.

\subsubsection{Universe of reference}

It is then a question of identifying the paradigms as sets of words which indicate the same referent. These words are used in coherence. We will notice that the same word by its polysemous character can belong to several universes of reference -as ecology, conception, hybrid, metaphor, organism, process, relation(ship), solution, etc.

The choice of the words and the creation of the universes of reference were mainly done by two factors. The usage of one software specialized on the analysis of the texts and the judgement of knowledge of the analyst (see Annexes 'List 2').

The table of the 'Evolution of Universes of Reference' -listed below- enables us to see the changes of the weight, therefore the importance and the power of the universes of reference in 50 years period. At this point of the research, according to the results, we are able to develop hypothesises like, technology gaining importance in the last period, philosophy living its place to moral philosophy as the ethics gains importance, society transferring into more the idea of 


\begin{tabular}{|c|c|c|c|c|c|c|c|c|c|c|}
\hline & \multirow{2}{*}{\multicolumn{2}{|c|}{$\begin{array}{r}1960-1969 \\
26 \text { texts }\end{array}$}} & \multirow{2}{*}{\multicolumn{2}{|c|}{$\begin{array}{r}1970-1979 \\
28 \text { texts } \\
\end{array}$}} & \multirow{2}{*}{\multicolumn{2}{|c|}{$\frac{1980-1989}{34 \text { texts }}$}} & \multirow{2}{*}{\multicolumn{2}{|c|}{$\begin{array}{r}1990-1999 \\
40 \text { texts }\end{array}$}} & \multirow{2}{*}{\multicolumn{2}{|c|}{$\begin{array}{r}2000-2008 \\
66 \text { texts }\end{array}$}} \\
\hline & & & & & & & & & & \\
\hline & WORD & VAL. & WORD & VAL. & WORD & VAL. & WORD & VAL. & WORD & VAL. \\
\hline & FORM & 59 & ARCHITECTURE & 110 & ARCHITECTURE & 192 & ARCHITECTURE & 257 & ARCHITECTURE & 252 \\
\hline & MEANING & 50 & BULLDNG & 62 & BULLDNG & 81 & ARCHITECT & 79 & SPACE & 198 \\
\hline & FROBLEM & 47 & CITY & 49 & FORM & 78 & DESIGN & 74 & NEW & 170 \\
\hline & CITY & 41 & ARCHITECT & 43 & DESIGN & 48 & BULDNG & 73 & DESIGN & 157 \\
\hline & BULDING & 29 & URBAN & 43 & CITY & 40 & CITY & 73 & BULLDING & 108 \\
\hline & DESIGN & 29 & FORM & 43 & URBAN & 35 & NEW & 52 & PROJECT & 92 \\
\hline & ORGANIZATION & 28 & SPACE & 37 & NEW & 35 & SPACE & 50 & CITY & 89 \\
\hline & TIME & 26 & SYSTEM & 36 & CULTURE & 27 & WORK & 45 & FORM & 87 \\
\hline & ENVIRONMENT & 25 & NEW & 35 & SPACE & 25 & PROJECT & 41 & WORK & 80 \\
\hline 10 & LIFE & 25 & DESIGN & 33 & MEANNG & 24 & FORM & 39 & ARCHITECT & 68 \\
\hline
\end{tabular}

Table of ponderation

\begin{tabular}{|l|r|r|r|r|r|}
\hline UNIV. REFERENCES & $1960-1969$ & $1970-1979$ & $1980-1989$ & $1990-1999$ & $2000-2008$ \\
\hline TECHNIQUE & $6,00 \%$ & $9,00 \%$ & $5,00 \%$ & $7,00 \%$ & $14,00 \%$ \\
\hline PHILOSOPHY & $20,00 \%$ & $13,50 \%$ & $13,00 \%$ & $7,00 \%$ & $6,00 \%$ \\
\hline SOCIETY & $10,00 \%$ & $13,50 \%$ & $16,50 \%$ & $22,00 \%$ & $17,00 \%$ \\
\hline THEORY & $13,00 \%$ & $13,50 \%$ & $19,00 \%$ & $19,00 \%$ & $14,00 \%$ \\
\hline ART & $0,20 \%$ & $0,50 \%$ & $2,00 \%$ & $2,00 \%$ & $3,00 \%$ \\
\hline HUMAN & $10,00 \%$ & $9,00 \%$ & $4,00 \%$ & $4,00 \%$ & $5,00 \%$ \\
\hline ETHICS & $7,00 \%$ & $16,00 \%$ & $13,00 \%$ & $16,00 \%$ & $14,00 \%$ \\
\hline HISTORY & $0,40 \%$ & $2,00 \%$ & $6,50 \%$ & $4,00 \%$ & $3,00 \%$ \\
\hline SYSTEM / RESEAU & $19,40 \%$ & $14,00 \%$ & $10,00 \%$ & $9,00 \%$ & $15,00 \%$ \\
\hline ENVIRONMENT & $6,00 \%$ & $5,00 \%$ & $4,00 \%$ & $5,00 \%$ & $5,00 \%$ \\
\hline SEMIOLOGY & $8,00 \%$ & $4,00 \%$ & $7,00 \%$ & $5,00 \%$ & $4,00 \%$ \\
\hline
\end{tabular}

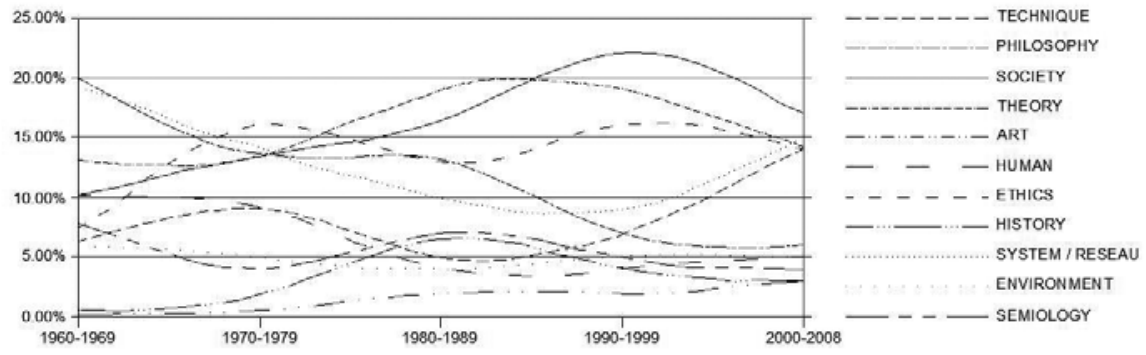

Evolution of universes of references

71 - ARCC Journal / Volume 5 Issue 2 - 71 
'social relationships', environment changing the content... from more general to specific character with the words as eco-system, biosphere, sustainable development, green design, hybrid, etc., having no more hierarchical share between nature and culture...

In order to deepen in the content of the texts, therefore more detailed weight of the universes of reference it is necessary to make a comparison between the 'Phase 1' and 'Phase 2' of lexocostatistic analysis. The table of 'Universes of reference 2000-2008 Phase 1 \& Phase 2' sheds light on the changes of the weight of the universes of reference for the period 2000-2008. As a result of this representation it is possible to observe the increase of the weight of 'philosophy' and the non-existence of 'art' and 'history.

\subsubsection{Typology}

The next challenge-aim of the research is to identify the obvious relations between the words, words and authors, and the possible regroupings. For that purpose we used a software of statistical analysis carrying out the analysis of the correspondences as the principle of explanation and also allowing the identification of the same groups of affinity. Therefore we retained the first 10 words of each text to establish the first typology starting from the statistical processing of a table 'attribute-object' where the authors are characterized by the words which they use. The following two representations of periods of 1990-1999 and 2000-2008 will permit us to identify and understand the eventual evolution of architecture terminology in the last 10 years of the last century and the first 8 years of the 21 st century. The aim will be to enlarge this analysis into 50 years in coming time.

In the representation of 'Factorial Analysis of Correspondences Period 2000-2008', in a system of axes, we realize that the whole of the components are organized around a first horizontal axis which can be interpreted as the axis "technological to social". The 'technological' dimension is indicated by the words "construction, material, perspective, physical, software, surface..." and the 'social' dimension by the words "city, communication, culture, junkspace, media, movement...". The vertical axis is interpreted as the axis "theoretical to practical". The 'theoretical' dimension is defined by the terms "complexity, conception, design, planning, question..." and the 'practical' dimension by the terms "builtform, fabric, function, language, pattern, textile...". These axes define 4 quadrants which contain each a group of components belonging to a certain characterized type.

The 1st type that we named as "theoretical-social" is characterized by the universes of references related to the society, theory, ethics, history and art. We find in this group the authors who are mainly theorists, historians like K. Frampton, J. Pallasmaa, Ch. Jencks. That seems coherent with the known status of these authors.

The 2nd type is called "theoretical-technique" and it is characterized by the universes of references technical, theoretical, philosophical, system-network and human. This quadrant mainly consists the terms related with the new way of representation and values related with new technology. We can find in this group the architect-author-educators like P. S. Cohen, P. Schumacher, K. Yeang, N. Callicott, M. Hengel and D. Sunguroglu. Here the bringing together of the 


\begin{tabular}{|l|r|r|}
\hline UNIV. REFERENCE & PHASE 1 & PHASE 2 \\
\hline TECHNIQUE & $14,00 \%$ & $11,00 \%$ \\
\hline PHILOSOPHY & $6,00 \%$ & $11,00 \%$ \\
\hline SOCIETY & $17,00 \%$ & $18,00 \%$ \\
\hline THEORY & $14,00 \%$ & $15,00 \%$ \\
\hline ART & $3,00 \%$ & $2,00 \%$ \\
\hline HUMAN & $5,00 \%$ & $5,00 \%$ \\
\hline ETHICS & $14,00 \%$ & $16,00 \%$ \\
\hline HISTORY & $3,00 \%$ & $1,00 \%$ \\
\hline SYSTEM / RESEAU & $15,00 \%$ & $14,00 \%$ \\
\hline ENVIRONMENT & $5,00 \%$ & $3,00 \%$ \\
\hline SEMIOLOGY & $4,00 \%$ & $4,00 \%$ \\
\hline
\end{tabular}

Universes of reference 2000-2008 Phase 1 \& phase 2

question of the relationship between the Technique and the Man seems as the continuation of the philosophical reflection of $\mathrm{M}$. Heidegger.

The 3rd type named "practical-technical" contains mostly technical and system-network references and the authors are mostly the architects, experts and critics like V. Croci, L. Bullivant, S. Johnson, Rahim\&Jamelle, C. Groothuizen which comment on the tendencies of architecture using new technologies. The new way of 'communication' with new technological possibilities can be identified as the dominant concept of this quadrant.

The 4th type named "practical-social" concernes mainly technical and social references. We find in this group the architects-researchers-educators who write about and present new technologies as N. Spiller, W. Aprile, S. Mirti, M. Garcia, A. Saggio and architects who use new technologies, have an international activity and are present in the media like H. Rashid (Asymptotic), Rahim \& Jamelle, C. Portzamparc, R. Koolhaas, D. Perrault, B. van Berkel.

It will remain to specify these configurations according to the enrichment of the corpus of texts and by comparison with the former periods.

For the period 1990-1999, the categorization of the texts and their authors are less obvious than the period 2000-2008, but we can however note that the terms related to the questions of society $(22 \%)$ are present in the whole of the texts. Two groups of universes of reference can be identified on both sides of the horizontal axis. The words which shows rather an ethical (16\%) positioning as 'ethical, choice, discussion, critical, tolerance, value, moral, wrong, pluralism, preference, political, responsible, difference' characterizing the first group in which we find architects practitioners and/or theorists like J. Nouvel, D. Libeskind, Mr. Botta; R. Koolhaas, D. Perrault, W. Alsop, but also Ch. Jencks, L. Krier, C. Correa, K. Frampton. The second group has rather theoretical (19\%) preoccupations defined by the words 'strategy, process, research, logic, paradigm, abstract, program, system, discipline, system, dissociation'. It is possible to find in this group Ph. Boudon, B. Russel, B. Tschumi, D. Libeskind (known at the same time as practitioner and theorist), S. Van der Ryn \& S. Cowan... In a context where the advent of new technologies as well as the emergence of environmental preoccupations take place, this period correspond to a reflexion focused on the social utility of the innovations associated with a discussion on the risks that these new objects can generate. The question of ethics is then indissociable from the questions of society. The theory relates to more the procedures than the products

73 - ARCC Journal / Volume 5 Issue 2 - 73 


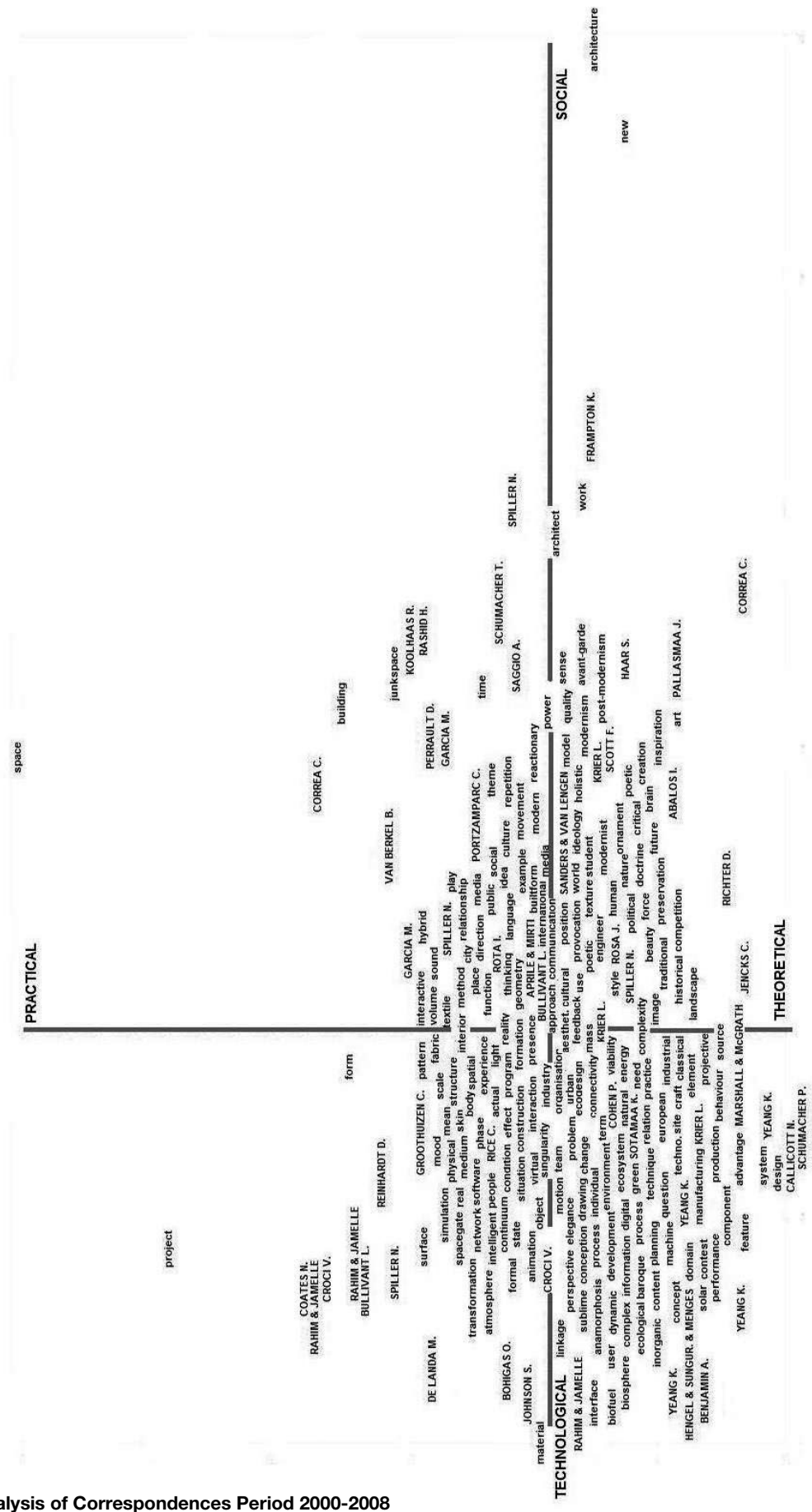

Factorial Analysis of Correspondences Period 2000-2008

74 - ARCC Journal / Volume 5 Issue 2 - 74 


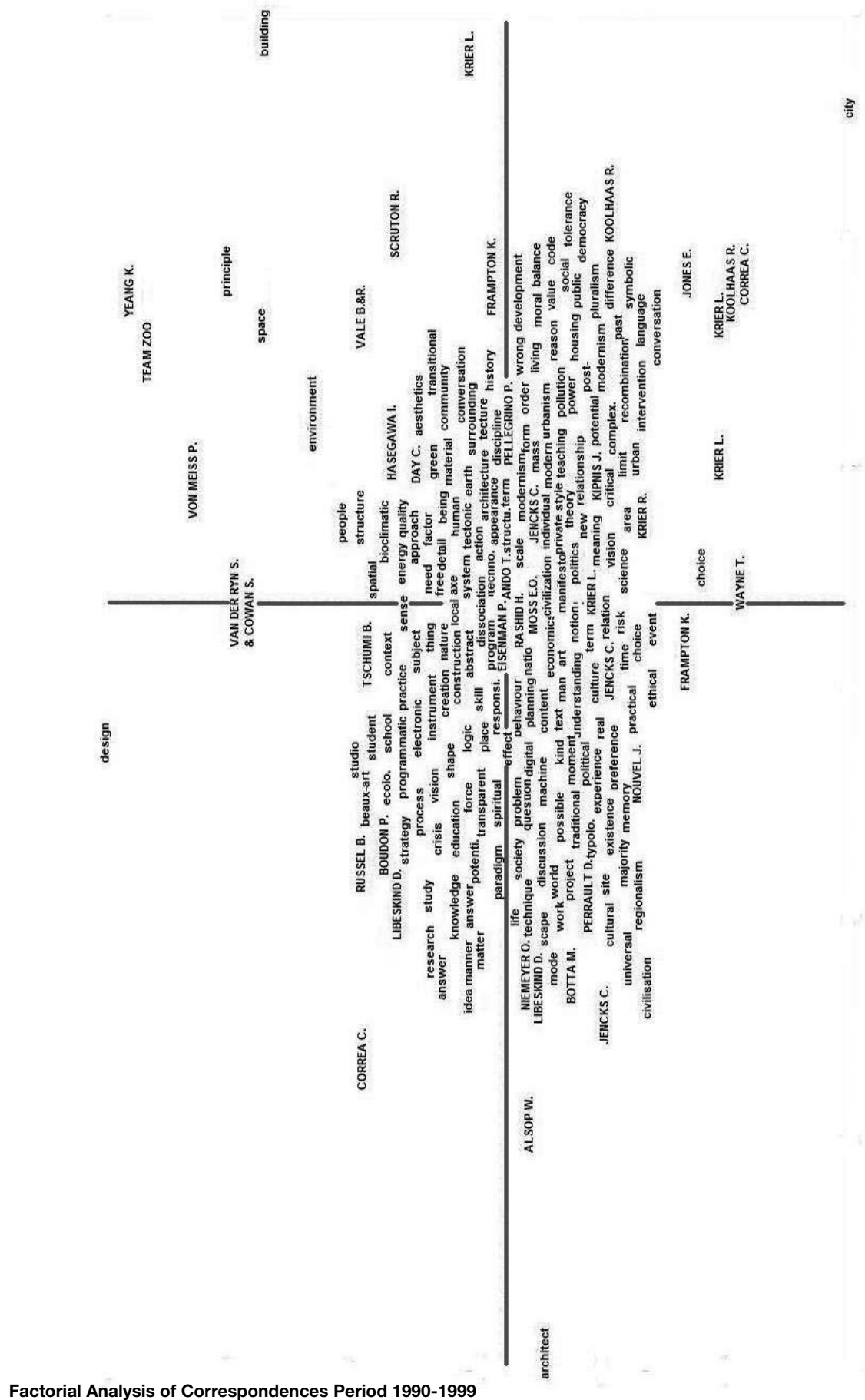

75 - ARCC Journal / Volume 5 Issue 2 - 75 
integrating an ethical point of view on the manner of transforming our society. In this state of the culture, the topics of art and history seem to take less importance in the field of architecture. This observation remains a subject of deepening in comparison with the development of the concept of 'heritage' and a new phenomenology suitable to transform our aesthetical vision of the world.

\section{Provisional Results}

3.1 We can consider that the structure of the field of architectural theory rests largely on the explicit or implicit relations of the discourses among themselves i.e. on the interdiscourses. Each discourse indeed takes a direction in a form of dependence to the other discourses by partly sharing the universes of references in which they are the various combinations of words which make it possible to identify a discourse, which is what makes its singularity even its new character.

3.2 The analysis of the discourses on architecture raises the question of a specific language, set of themes suitable to found the architectural discipline.

3.3 We can also wonder about the theoretical value of the discourses by the examination of the lexicons used, the use of general or specific terms which can result either in 'talking to say nothing' (neutral terms) or to set up concepts that base on a lexicon of speciality.

3.4 The diachronic study should show an evolution of the vocabulary, the appearance, the transformation, the disappearance or the continuity of the paradigms. Therefore we could identify some new terms like "interactivity, interface, Internet, hybrid, software...", new values as "ecology, green design, sustainable development, digital, virtual", new meanings like "machine, surface, skin..." or words which rarefy like "function, theory..." posing the assumption of a language of generations.

3.5 The assumption of a local language whose challenge is the question of interculturality also remains to be checked. For example is there a specific architectural thought by its own in the Anglo-Saxon world influenced by the use of a language?

3.6 Is it possible to realize a project of a dictionary of terms of the architectural discourses conceived as a bank of data which should be updated permanently within the framework of an international collaboration?

3.7 Finally the reality does not pre-exist in the discourses but is built by the discourses, theory or doctrines, which evoke a possible world and justify the study that we propose to realize.

\section{References}

AUSTIN, J.L., Quand dire, c'est faire, trad. fr., Paris, Seuil, 1970

BOURDIEU, P., Ce que parler veut dire, Paris, Fayard, 1982

CHAREAUDEAU, P., MAINGUENEAU, D ., (sous la direction de ), Dictionnaire d'analyse du discours, Paris, Seuil, 2002

KUHN, Th., La structure des révolutions scientifiques, trad. fr., Paris, Flammarion, 1983

LYOTARD, J.F., La condition postmoderne, Paris, Les Editions de Minuit, 1977

76 - ARCC Journal / Volume 5 Issue 2 - 76 


\section{LIST 1. 'THE FIRST 10 MOST COMMONLY USED WORDS'}

\section{Period 1960-1969}

Aesthetics, Ambiguity, Analyse, Analysis, Aptitude, Architect, Architecture, Area, Art, Artefact, Awareness, Building, Change, City, Complex, Complexity, Component, Concept, Conception, Confidence, Conflict, Connection, Context, Contradiction, Control, Craftsman, Creation, Creator, Culture, Design, Desire, Destruction, Development, Diagram, Discipline, Dissociation, Double, Dynamic, Ecology, Edge, Element, Elimination, Energy, Environment, Environmental, Equivoque, Evolution, Express, Expression, Fact, Fitting, Flexibility, Form, Function, Heterotopia, History, Historical, House, Housing, Human, Humanity, Idea, Image, Individual, Information, Innocence, Intellect, Knowledge, Landmark, Landscape, Language, Lattice, Life, Light, Logic, Man, Mass, Material, Meaning, Mechanical, Mega structure, Megaword, Metaphor, Method, Mind, Model, Modern, Monument, Multivalent, Natural, Nature, Negentrophy, Node, Nothing, Obligation, Obsolescence, Order, Organisation, Organism, Participation, Passionate, Path, Pattern, Peasant, People, Physical, Place, Planning, Principle, Problem, Process, Productivity, Project, Real, Reality, Reference, Relation, Relationship, Research, Reseau, Science, Self-confidence, Sense, Sign, Site, Society, Solution, Something, Space, Structure, Support, System, Technique, Technology, Term, Thing, Thought, Time, Town, Tradition, Tree, Truth, Unit, Unity, Unselfconsciousness, Urban, Village, What

\section{Period 1970-1979}

Alive, Analogical, Anti-scheme, Architect, Architecture, Archetypical, Aspect, Attitude, Belief, Block, Body, Boundary, Bricolage, Building, Capitalist, Choice, Choreography, City, Coincidence, Collage, Collision, Concept, Conception, Condition, Construction, Context, Continuum, Contradiction, Conventional, Creation, Critical, Criticism, Cultural, Culture, Delight, Design, Desire, Desolation, Development, Dialectic, Different, Dimension, Drawing, Dynamic, Economical, Electronics, Element, Energy, Environment, Everything, Existing, Experience, Explicit, Flow, Force, Form, Formal, Function, Functionalist, Future, Geometrical, Geometry, Great, Growth, Heroic, Hierarchy, History, Human, Humanist, Idea, Ideal, Ideology, Image, Information, Institution, Integral, Interest, Interpretation, Landscape, Language, Level, Life, Light, Limit, Man, Manifesto, Meaning, Memory, Method, Mind, Modern, Modernism, Morphology, Motion, Movement, Natural, Nature, Need, New, Object, Objective, Order, Ordinary, Original, Paradigm, Pattern, People, Piece, Place, Pleasure, Political, Politics, Population, Preference, Problem, Project, Public, Quality, Quarter, Radical, Rational, Realisation, Reality, Reconstruction, Relation, Relationship, Research, Result, Retroactive, Satisfactory, Sculpture, Sign, Size, Society, Solution, Space, Spatial, Spirit, Square, Street, Structure, Suburb, System, Technique, Technology, Tendency, Term, Text, Theoretical, Theory, Thought, Thick, Town, Type, Typology, Unbalancing, Understanding, Urban, Volume, Waste, Word, World

\section{Period 1980-1989}

Action, Aesthetics, Age, Approach, Architect, Architecture, Area, Art, Aspect, Avant-Garde, Basic, Beauty, Building, Capacity, Centre, Changement, Changing, City, Classical, Classicism, Cohesion, Component, Concept, Condition, Connection, Construction, Constructional, Context, Contradiction, Critic, Critical, Cultural, Culture, Decision, Deconstructivist, Density, Design, Developer, Difference, Dimension, Discourse, Disjunction, Diversity, Domestic, Drawing, Dream, Eclecticism, Economic, Effect, Element, Enclosure, End, Energy, Environment, Equality, Expression, External, Face, Filed, Figurative, Flexible, Form, Formal, Functional, Future, Geometry, Great, Group, Historical, History, Housing, Human, Idea, Ideology, Image, Imagery, Individual, Industrial, Innovation, Knowledge, Landscape, Laws, Legible, Life, Light, Logic, Material, Mathematical, Meaning, Metaphor, Metaphysical, Method, Model, Modern, Modernism, Modernist, Movement, Myth, Nature, Negotiation, Neighbourhood, New, Not-classical, Notion, Object, Open, Order, Origin, Pattern, People, Phenomena, Physical, Place, Plan, Plurality, Popular, Post-Modernism, Power, Principle, Private, Problem, Process, Product, Program, Project, Psychological, Public, Pure, Question, Radical, Randomness, Ratio, Rational, Realisation, Reality, Realm, Regionalism, Regionalist, Relation, Renovation, Representation, Role, Rule, Rupture, Science, Shelter, Side, Signification, Site, Situation, Skill, Social, Society, Sociological, Solution, Source, Space, Strategy, Structure, Style, Structure, Style, Surface, Symbiosis, Symbol, System, Team, Tectonic, Tendency, Thematic, Theme, Theory, Thinking, Time, Timeless, Tradition, Traditional, Transform, Transformation, Translate, Uni-

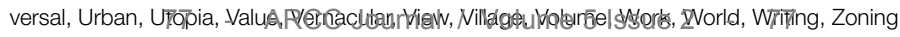




\section{Period 1990-1999}

Abstract, Action, Aesthetics, Answer, Appearance, Approach, Architect, Architectural, Architecture, Area, Art, Axe, Balance, Beaux-Art, Behaviour, Being, Bigness, Bioclimatic, Building, Choice, City, Civilisation, Code, Community, Complexity, Conversation, Construction, Content, Context, Conversation, Course, Creation, Crisis, Critical, Cultural, Culture, Democracy, Design, Detail, Development, Difference, Digital, Discipline, Discussion, Dissociation, Earth, Ecological, Ecology, Economics, Education, Electronic, Effect, Energy, Environment, Ethical, Event, Existence, Experience, Facture, Figure, Folding, Force, Form, Free, Green, Height, History, Housing, Human, Idea, Individual, Instrument, Intervention, Kind, Knowledge, Language, Life, Limit, Living, Local, Logic, Machine, Majority, Man, Manifesto, Manner, Mass, Material, Material, Meaning Memory, Mode, Modern, Modernism, Moment, Moral, National, Nature, Need, New, Notion, Object, Order, Paradigm, Past, People, Place, Planning, Pluralism, Plurality, Political, Politics, Pollution, Possible, Post-Modern, Post-Modernism, Potential, Power, Practical, Practice, Prediction, Preference, Principal, Principle, Private, Problem, Process, Program, Programmatic, Project, Public, Quality, Question, Real, Reason, Recombination, Regionalism, Relation, Relationship, Research, Responsibility, Risk, Scale, Scape, School, Science, Sense, Shape, Site, Skill, Social, Society, Space, Spatial, Spiritual, Strategy, Structural, Structure, Student, Studio, Study, Style, Subject, Surrounding, Symbolic, System, Teacher, Teaching, Technique, Technology, Tectonic, Term, Text, Theory, Thing, Time, Tolerance, Traditional, Transitional, Transparent, Typology, Understanding, Universal, Urban, Urbanism, Value, Vision, Work, World, Wrong

\section{Period 2000-2008}

Actual, Advantage, Aesthetics, Anamorphosis, Animation, Approach, Architect, Architectural, Architecture, Art, Atmosphere, Attractor, Avant-Garde, Baroque, Beauty, Behaviour, Behavioural, Biofuel, Biosphere, Body, Brain, Building, Builtform, Camouflage, Change, City, Classical, Communication, Competition, Complex, Complexity, Component, Composition, Concept, Conception, Condition, Connectivity, Construction, Content, Contest, Continuum, Craft, Creation, Critical, Cultural, Culture, Design, Designer, Development, Difference, Digital, Direction, Display, Doctrine, Domain, Drawing, Dynamic, Ecodesign, Ecological, Ecosystem, Education, Effect, Elegance, Elegant, Element, Energy, Engineer, Engineering, Environment, European, Example, Exclusion, Experience, Fabric, Fabrication, Feature, Feedback, Flow, Force, Form, Formal, Formation, Function, Future, Geometry, Green, Historic, Holistic, Human , Hybrid, Idea, Ideology, Image, Imagined, Individual, Industrial, Industry, Information, Inorganic, Inspiration, Intelligent, Interaction, Interactive, Interactivity, Interface, Interior, International, Junckspace, Landscape, Language, Light, Linkage, Local, Machine, Manufacturing, Mass, Material, Mean, Media, Medium, Method, Model, Modern, Modernism, Modernist, Mood, Motion, Movement,Natural, Nature, Need, Network, New, Object, Organisation, Ornament, ParanoiacCritical, Patch, Pattern People, Performance, Perspective, Phase, Photobioreactor, Physical, Piece, Place, Planning, Play, Poetic, Political, Position, Possibility, Post-Modernism, Potentiality, Power, Practice, Presence, Preservation, Prisoner, Problem, Process, Production, Program, Project, Projective, Provocation, Public, Quality, Question, Reactionary, Real, Reality, Relation, Relationship, Repetition, Scale, Sense, Shade, Simulation, Singularity, Site, Situation, Skin, Social, Software, Solar, Sound, Source, Space, Space gate, Spatial, State, Structure, Student, Style, Sublime, Surface, System, Team, Technique, Technology, Term, Textile, Texture, Theme, Thinking, Time, Tradition, Traditional, Transformation, Urban, Urbanism, Use, User, Viability, Virtual, Visual, Volume, Work, World 
LIST 2. 'THE UNIVERSES OF REFERENCE'

\section{Period 1960-1969}

UNIVERSES

OF REFERENCE

TECHNIQUE

PHILOSOPHY

SOCIETY

THEORY

ART

HUMAN

ETHICS

HISTORY

SYSTEM/RESEAU

ENVIRONMENT

SEMIOLOGY
PERCENT. WORDS

6.00\% Building, component, element, light, material, mechanical, megastructure, structure, technical, technology...

20.00\% Ambiguity, artefact, change, concept, conception, contradiction, double, ecology, equvoque, evolution, fact, heteropia, idea, language, life, light, logic, material, metaphor, multivalent, nothing, order, organism, philosophy, reality, reference, sense, thing, thought,time, truth, unity, unselfconsciousness, what...

10.00\% Architect, area, city, craftsman, culture, development, evolution, house, housing, mass, peasant, people, place, productivity, realtionship, society, town, urban, village, ...

13.00\% Analyse, concept, conception, creation, design, discipline, dissociation, fitting, idea, knowledge, logic, method, model, pattern, principle, problem, process, project, research, science, solution, term, tree...

0.20\% Aesthetics, art, ...

$10.00 \% \quad$ Aptitude, creator, desire, evolution, human, individual, innocence, intellect, landmark, life, man, mind, passionate, path, physical, self confidance, unselfconsciousness...

7.00\% Awareness, confidence, conflict, destruction, ecology, elimination, ethics, mind, obligation, order, participation, truth, ...

0.40\% Historic, historical, history, modern, monument, tradition, ...

19.40\% Artefact, complex, complex, connection, control, diagram, dynamic, element, energy, flexibility, function, information, lattice, megastructure, megaword, method, model, negentrophy, network, node, obsolescence, order, organisation, pattern, planning, relation, reseau, solution, structure, support, system/reseau, tree, unit, ...

6.00\% Context, development, ecology, environment, landscape, natural, nature, organism, site, ...

Double, express, expression, form, image, language, meaning, meta phor, multivalent, sense, sign, ... 
Period 2000-2008

UNIVERSES OF

REFERENCE

TECHNIQUE

PHILOSOPHY

SOCIETY

THEORY

ART

HUMAN

ETHICS

HISTORY

$3.00 \%$

SYSTEM/RESEAU

ENVIRONMENT

$5.00 \%$

SEMIOLOGY

$4.00 \%$
PERCENT. WORDS

14.00\% Animation, building, builtform, component, construction, digital, drawing, energy, engineering, fabric, fabrication, geometry, green, industrial, industry, light, machine, material, perspective, photobioreactor, physical, power, shade, skin, software, solar, sound, spacegate, structure, surface, technique, technology, textile, texture, volume, ...

6.00\% Difference, doctrine, green, holistic, hybrid, idea, ideology, intelligent, linkage, machine, nature, projective, real, reality, thinking, ...

$17.00 \%$ Actual, architect, change, city, complex, continuum, craft, creation, cultural, culture, designer, development, dynamic, education, european, exclusion, formation, ideology, individual, industrial, industry, interior, international, junkspace, local, mass, media, medium, mood, movement, need, new, people, public, relationship, similarity, social, student, team, traditional, urban, urbanism, use, user, work, world, ... 14.00\% Advantage, approach, complex, composition, concept, conception, condition, content, design, domain, ecodesign, example, experience, form, formal, function, method, object, patch, pattern, planning, possiblity, practice, problem, process, production, program, project, question, repetition, scale simulation, source, space, spatial, theme, ... Aesthetics, art, Baroque, beauty, poetic, style, sublime, ...

Behaviour, behavioural, body, brain, human, individual, inspritation, modernist, paranoiac critical, poetic, user, visual, ...

14.00\% Atmosphere, avantgarde, camouflage, change, competition, contest, critical, difference, direction, ecodesign, ecological, elegance, elegant, european, exclusion, force, future, green, ideology, international, linkage, motion, ornament, physical, political, position, power, preservation, prisoner, provocation, quality, reactionary, relation, solar, viability, world, ...

Avantgarde, Baroque, classical, historic, modern, modernism, modernist,...

15.00\% Attractor, communication, complexity, component, connectivity, development, digital, display, effect, element, energy, feature, feedback, flow, function, information, interaction, interactive, interactivity, interface, network, organisation, pattern, performance, phase, piece, play, possiblity, potentiality, presence, relationship, simulation, source, state, structure, system, term, time, transformation, virtual, ...

Biofule, biosphere, ecosystem, environment, hybrid, inorganic, landscape, natural, nature, place, site, situation, ...

Anamorphosis, image, imagined, language, mean, sense, surface, virtual, visual, $\ldots$ 